ARTICLE

Received 12 Jun 2014 | Accepted 30 Oct 2014 | Published 8 Dec $2014 \quad$ DOl: 10.1038/ncomms6707

\title{
Asymmetric total synthesis of $(-)$-lingzhiol via a Rh-catalysed [3+2] cycloaddition
}

Rong Long ${ }^{1,2, \star}$, Jun Huang ${ }^{1,2, \star}$, Wenbin Shao ${ }^{1,2}$, Song Liu ${ }^{3}$, Yu Lan ${ }^{3}$, Jianxian Gong ${ }^{1,2} \&$ Zhen Yang ${ }^{1,2,4}$

The development of efficient reactions for the one-pot construction of bicyclic ring systems bearing two quaternary carbon centres at their bridgehead positions represents a significant challenge to synthetic chemistry. The development of new methods capable of overcoming this challenge is highly desirable, because this motif can be found in a wide range of natural products with significant biological activities. Herein, we report an efficient [3+2] cycloaddition reaction between an enal and an alleno rhodium species, which was generated in situ from the corresponding enynol via a retro metal-propargylation reaction, to give [3.3.0] and [3.4.0] bicyclic systems bearing two quaternary atoms at their bridgehead positions. The developed chemistry has been successfully applied to the asymmetric total synthesis of natural product ( - )-lingzhiol (4) for the first time in 17 steps.

\footnotetext{
${ }^{1}$ Laboratory of Chemical Genomics, School of Chemical Biology and Biotechnology, Peking University Shenzhen Graduate School, Shenzhen 518055, China. ${ }^{2}$ Key Laboratory of Bioorganic Chemistry and Molecular Engineering of Ministry of Education, Beijing National Laboratory for Molecular Science (BNLMS), and Peking-Tsinghua Center for Life Sciences and Academy for Advanced Interdisciplinary Studies, Peking University, Beijing 100871, China. ${ }^{3}$ School of Chemistry and Chemical Engineering, Chongqing University, Chongqing 400030, China. ${ }^{4}$ Key Laboratory of Marine Drugs, Chinese Ministry of Education, School of Medicine and Pharmacy, Ocean University of China, 5 Yushan Road, Qingdao 266003, China. * These authors contributed equally to this work. Correspondence and requests for materials should be addressed to Y.L. (email: lanyu@cqu.edu.cn) or to J.G. (email: gongjx@pku.edu.cn) or to Z.Y. (email: zyang@pku.edu.cn)
} 
A wide variety of intriguing natural products with fivemembered [3.3.0] and [4.3.0] carbobicyclic ring systems and two vicinal stereogenic quaternary carbon centres at the ring junction have been identified to exhibit significant biological activities that could potentially be used to develop new drugs ${ }^{1-6}$. Subergorgic acid (1 in Fig. 1a), isolated from the Pacific gorgonian coral Subergorgia subeross, showed cardiotoxic activity ${ }^{1}$. Crinipellin A (2), isolated from the fungus Crinipellis stipitaria (Agaricales), has been reported to exhibit potent antibiotic activity ${ }^{2}$. Retigeranic acid (3) is a representative member of the sesterterpenoid family of compounds and exhibits a broad range of biological activities ${ }^{3-7}$. Although compounds of this type are well known to elicit a variety of interesting biological responses, efficient methods for their construction are scarce. New synthetic strategies and methodologies are therefore required to provide facile access to these natural products and their analogues, to allow for the development of new therapeutic agents and drugs.
The construction of vicinal quaternary carbon centres, however, represents a significant challenge in natural-product synthesis ${ }^{8}$. Despite significant progress in this area during the last two decades towards the stereoselective synthesis of vicinal quaternary carbon centres ${ }^{9-16}$, there are currently no efficient reactions available for the enantioselective construction of [3.3.0] and [4.3.0] bicyclic ring systems $s^{17,18}$ bearing two quaternary carbon centres at their bridgehead positions. This lack of suitable synthetic methodologies has therefore limited the in-depth exploitation of the biological and pharmaceutical value of these natural products.

Five-membered carbocycles can be constructed according to reactions between $3-\mathrm{C}$ and 2-C units ${ }^{19,20}$. Danheiser and Becker ${ }^{21}$ reported the use of an allene as a three-carbon synthon in their $[3+2]$ cycloaddition reaction of Si-substituted allenes (Fig. 1b). In a separate study, Lu et al. ${ }^{22,23}$ reported the development of a phosphine catalysed [3+2] cycloaddition reaction. Recently, phosphine-catalysed regio- and enantio-selective

a Representative natural products<smiles>C=C1C[C@H](C)[C@H]2CC[C@]3(C)C=C(C(=O)O)C(=O)C123</smiles>

Subergorgic acid (1)

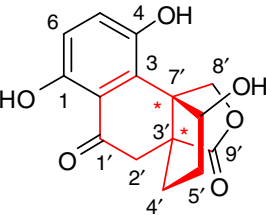

(-) -lingzhiol (4)

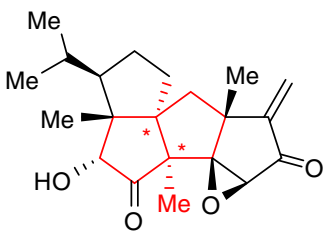

Crinipellin A (2)

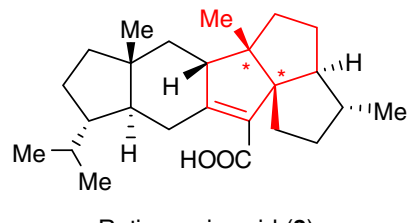

Retigeranic acid (3)

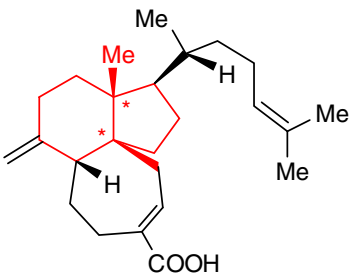

Gascardic acid (6)

b

[3+2] cycloaddition<smiles>C=C=C(C)[Sn]</smiles><smiles>O=C1C=CCCC1</smiles><smiles>[123IH]</smiles><smiles>CC1=C([SiH3][13CH3])CC2CCCC(=O)C12</smiles><smiles>C=CC(C)=O</smiles><smiles>COC(=O)C=CC(C)=O</smiles><smiles></smiles><smiles>COC(=O)C1=CC[C@@H](C(C)=O)[C@H]1C(C)=O</smiles>

\section{C}

Rh-catalyzed [3 +2$]$ cycloaddition (this work)

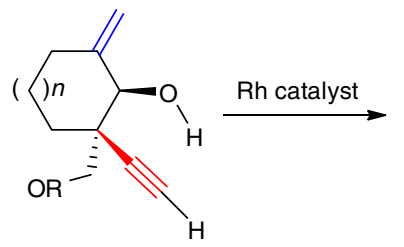<smiles>C=C(C=O)/C(C=Cc1ccccc1)=C/CCC</smiles>

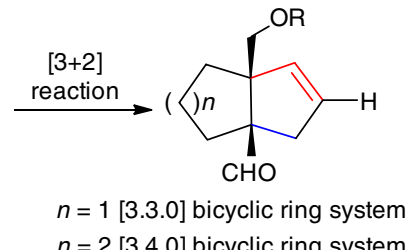

Figure 1 | Representative natural products containing five-membered carbocycles and their synthetic methods. (a) Selected biologically active natural products bearing bridgehead functionalized [3.3.0] fused rings and [3.4.0] fused rings. (b) Lewis acid-promoted and phosphine-catalysed [3 +2 ] cycloaddition of allenoates to construct five-membered carbocycles. (c) Our strategy to access both [3.3.0] and [4.3.0] bicyclic ring systems via Rhcatalysed $[3+2]$ cycloaddition. 
$[3+2]$ cycloadditions of allenoates with electron-deficient olefins and imines-a process that provided efficient access to a variety of synthetically useful carbo- and hetereocycles-have received considerable research interest, and significant progresses have been elegantly demonstrated by different groups ${ }^{24-33}$. Despite the above impressive achievements, there is an urgent need for the development of efficient $[3+2]$ cycloaddition reaction to enable the direct and stereoselective syntheses of [3.3.0] and [4.3.0] bicyclic ring systems bearing two quaternary carbon centres at their bridgehead positions.

As a useful nucleophile, allenyl metal species can react with a wide variety of electrophiles ${ }^{34-36}$ and, consequently, these adducts have been applied to the syntheses of a broad range of structurally diverse compounds ${ }^{37-39}$. However, the use of allenyl rhodium species in organic synthesis remains scarce ${ }^{40-42}$.

With this in mind, and as part of our ongoing work towards the development of efficient methods for the total synthesis of natural products, we investigated the use allenyl rhodium species as three-carbon synthons in organic synthesis. It was envisaged that the use of an $\alpha, \beta$-unsaturated aldehyde linked to an allenyl rhodium moiety could be used for an intramolecular $[3+2]$ cycloaddition reaction, which would allow for the formation of a cyclopentane ring ${ }^{43,44}$. Herein, we report the development of a new $[3+2]$ cycloaddition reaction between an enal and an alleno rhodium species, which was generated in situ by the Rh(I)mediated retro-propargylation of homo-propargyl alcohol ${ }^{45}$, to give [3.3.0] and [4.3.0] bicyclic ring systems bearing two quaternary carbon centres at the bridgehead positions (Fig. 1c). Notably, the use of chiral starting materials in this reaction led to the unprecedented synthesis of enantiomerically pure [3.3.0] bicyclic products, representing a significant development in terms of the application of this reaction to the total synthesis of naturally occurring biologically active chiral molecules. Furthermore, this newly developed reaction has been successfully applied to the total synthesis of natural product

\begin{tabular}{|c|c|c|c|}
\hline & $\underbrace{O H}_{7 a}$ & 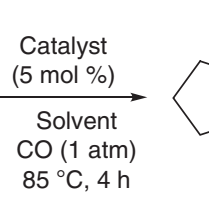 & \\
\hline Entry & Catalyst & Solvent & Yield (\%) \\
\hline 1 & {$[\mathrm{RhCl}(\mathrm{cod})]_{2}$} & Toluene & 23 \\
\hline 2 & {$[\mathrm{RhCl}(\mathrm{cod})]_{2}$} & $\mathrm{ClCH}_{2} \mathrm{CH}_{2} \mathrm{Cl}$ & 75 \\
\hline 3 & $\mathrm{Rh}\left(\mathrm{PPh}_{3}\right)_{3} \mathrm{Cl}$ & $\mathrm{ClCH}_{2} \mathrm{CH}_{2} \mathrm{Cl}$ & 0 \\
\hline 4 & $\mathrm{RhCO}\left(\mathrm{PPh}_{3}\right)_{3} \mathrm{Cl}$ & $\mathrm{ClCH}_{2} \mathrm{CH}_{2} \mathrm{Cl}$ & $<5$ \\
\hline 5 & {$\left[\mathrm{Rh}\left(\mathrm{C}_{7} \mathrm{H}_{8}\right)_{2}\right] \mathrm{BF}_{4}$} & $\mathrm{ClCH}_{2} \mathrm{CH}_{2} \mathrm{Cl}$ & 16 \\
\hline 6 & {$[\mathrm{RhOH}(\mathrm{cod})]_{2}$} & $\mathrm{ClCH}_{2} \mathrm{CH}_{2} \mathrm{Cl}$ & 48 \\
\hline 7 & {$\left[\mathrm{RhCl}(\mathrm{CO})_{2}\right]_{2}$} & $\mathrm{ClCH}_{2} \mathrm{CH}_{2} \mathrm{Cl}$ & 87 \\
\hline 8 & {$\left[\mathrm{RhCl}(\mathrm{CO})_{2}\right]_{2}$} & $\mathrm{ClCH}_{2} \mathrm{CH}_{2} \mathrm{Cl}$ & $45^{\dagger}$ \\
\hline 9 & {$\left[\mathrm{RhCl}(\mathrm{CO})_{2}\right]_{2}$} & $\mathrm{MeCN}$ & $<5$ \\
\hline 10 & {$\left[\mathrm{RhCl}(\mathrm{CO})_{2}\right]_{2}$} & THF & 17 \\
\hline 11 & {$\left[\mathrm{RhCl}(\mathrm{CO})_{2}\right]_{2}$} & 1,4-dioxane & 0 \\
\hline
\end{tabular}

lingzhiol, which is reported to be an important agent for the study and treatment of diabetic nephropathy ${ }^{4}$.

\section{Results}

Optimization of the reaction conditions. During the course of this study, compound $7 \mathbf{a}$ (entry 1 in Table 1), which contained a homo-propargyl alcohol and a terminal alkene, was converted to $7 \mathbf{b}$ in $23 \%$ yield as a single diastereoisomer in the presence of $[\mathrm{RhCl}(\mathrm{cod})]_{2}(5 \mathrm{~mol} \%)$ under a balloon pressure of $\mathrm{CO}$. The structure of 7a was confirmed by X-ray crystallographic analysis of its precursor diol, and this observation inspired us to investigate this reaction in greater detail.

Initial optimization of the reaction conditions have been performed on studying the effects of various reaction parameters on the outcome of the reaction, including the type of rhodium catalyst, the solvent and the temperature. Of the different rhodium catalysts and solvents tested, $\left[\mathrm{RhCl}(\mathrm{CO})_{2}\right]_{2}$ (refs 46-48) in $\mathrm{ClCH}_{2} \mathrm{CH}_{2} \mathrm{Cl}$ was found to be optimal. To demonstrate the catalytic role of the rhodium catalyst, the annulation reaction of $7 \mathbf{a}$ was conducted in the absence of $\left[\mathrm{RhCl}(\mathrm{CO})_{2}\right]_{2}$; as a result, no annulated product $7 \mathbf{b}$ was observed, indicating that the rhodium catalyst was essential to the success of the reaction. We then carried out the reaction below $80^{\circ} \mathrm{C}$ and the reaction became sluggish, which resulted in lower yields of the annulated product $\mathbf{7 b}$. The results of these screening experiments were combined into a single optimized procedure involving the use of a catalytic amount of $\left[\mathrm{RhCl}(\mathrm{CO})_{2}\right]_{2} \quad(5 \mathrm{~mol} \%)$ at a temperature of $85^{\circ} \mathrm{C}$ under a positive pressure of $\mathrm{CO}$ (balloon) in $\mathrm{ClCH}_{2} \mathrm{CH}_{2} \mathrm{Cl}$, which gave the annulated $\mathbf{7 b}$ in an isolated yield of $87 \%$ (entry 7 in Table 1).

It is noteworthy that these reactions had to be conducted under an atmosphere of $\mathrm{CO}$. When the reaction was conducted in the absence of $\mathrm{CO}$, the desired product $\mathbf{7 b}$ was formed in a reduced yield of only $45 \%$ (entry 8 in Table 1 ). To determine whether the observed low yield occurred as a consequence of a Rh-catalysed decarbonylation ${ }^{49}$ reaction, we monitored the reaction by highresolution mass spectroscopy, although the results of this analysis failed to identify the formation of a decarbonylative species during the course of the reaction (Supplementary Fig. 80). Based on these results, it was proposed that under an atmosphere of $\mathrm{CO}$, the decomposition of $\left[\mathrm{RhCl}(\mathrm{CO})_{2}\right]_{2}$ catalyst was in part prohibited, thus facilitating the conversion from $7 \mathbf{a}$ to $7 \mathbf{b}$.

Substrate scope. To assess the scope and generality of the optimized reaction conditions, we prepared enynols $\mathbf{8 a - 1 4 a}$ in their racemic forms and investigated their annulation under the conditions listed in Table 2. Substrates 8a-11a, bearing an ether, ester or carboxylate substituent (Table 2, entries 2-4), can give the corresponding annulated products $\mathbf{8 b} \mathbf{- 1 1} \mathbf{b}$ in good-to-excellent yields (68-98\%). Furthermore, the alkyne moiety of the substrate could be substituted with an aromatic group, which demonstrated that moderate reaction yields could be achieved in most cases (Table 2, entry 6). However, when the substrates bear a bromine substituent at the terminal alkyne position (entry 5, 12a), or two methyl groups at the exocyclic methylene positions (entry 7, 14a), the yields for the annulation are relatively low due to the substrate decomposition under the standard conditions.

The annulation reaction is also compatible with the presence of a bromine substituent at the terminal alkyne position, although the corresponding $[3+2]$ product $\mathbf{1 2 b}$ was isolated in low yield due to the stability problems. The substitution of the exocyclic methylene group with two methyl groups was also well tolerated under the optimized conditions (Table 2, entry 7), with the annulated product $\mathbf{1 4 b}$ being isolated in a yield of $43 \%$. This particular example highlights the potential value of applying our 
Table 2 | Synthesis of the [3,3,0]-bicyclic scaffolds.

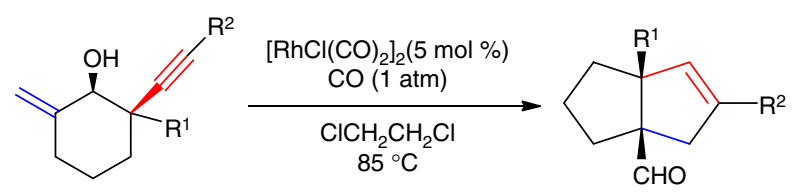

Time (h) Yield ${ }^{*}$

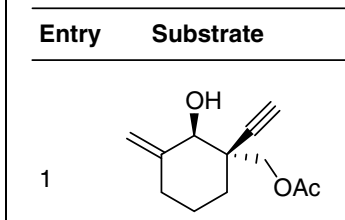

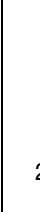

2<smiles>C#C[C@]1(CO[PbH2])CCCC(=C)[C@@H]1O</smiles>

3<smiles>C#C[C@]1(COP)CCCC(=C)[C@@H]1O</smiles>

$10 \mathrm{a}$

$\mathrm{P}=\mathrm{NO}_{2} \mathrm{PhCO}$<smiles>C#C[C@]1(C(=O)OCC)CCCC(=C)[C@@H]1O</smiles>

$11 \mathrm{a}$<smiles>C=C1C[14C](=O)[C@H](OC(C)=O)C1(C#CBr)C#CBr</smiles><smiles>[R3][13c]1ccccc1C#C[C@]1(COC(=O)[O-])CCCC(=C)[C@@H]1O</smiles><smiles>C#C[C@]1(C(=O)OCC)CCCCC1=C(C)C</smiles>

Product<smiles>CC(=O)OC[C@]12C=CC[C@]1(C=O)CCC2</smiles>

8b

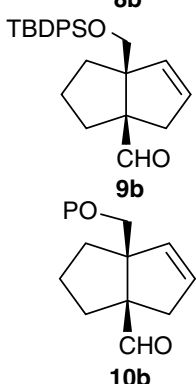

X-ray crystallography<smiles>CCOC(=O)[C@]12C=CC[C@]1(C=O)CCC2</smiles>

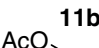<smiles>O=C[C@]12CCC[C@]1(COC1CCCCC1)C=C(Br)C2</smiles>

24

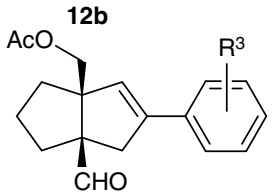

13ba $\left(\mathrm{R}^{3}=\mathrm{H}\right)$

13bb $\left(\mathrm{R}^{3}=p-\mathrm{Me}\right)$

13bc $\left(\mathrm{R}^{3}=p\right.$-OMe $) \quad 8$

13bd $\left(\mathrm{R}^{3}=p-\mathrm{F}\right)$

13be $\left(\mathrm{R}^{3}=0\right.$-OMe) 72

13bf $\left(\mathrm{R}^{3}=\mathrm{o}-\mathrm{NO}_{2}\right) \quad 72$

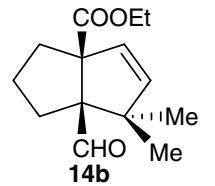

8

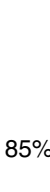

$30 \%$

8

8

8

$98 \%$

$5 \%$

$18 a$<smiles>C#C[C@]1(C(=O)OCC)CCCCC(=C)[C@@H]1O</smiles>

X-ray crystallography

5
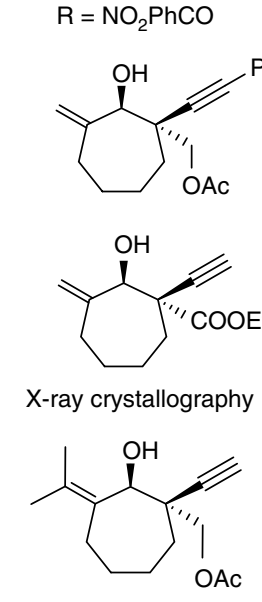

$15 b$

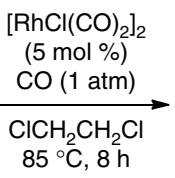

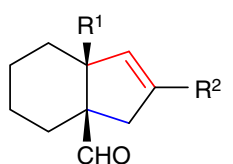

Product<smiles></smiles>

$16 b$<smiles>O=C[C@]12CC=C[C@@]1(CO)CCCC2</smiles>

$95 \%$

X-ray crystallography

$17 b$<smiles>CC(=O)OC[C@]12C=C(c3ccccc3)C[C@]1(C=O)CCCC2</smiles>

$51 \%$

$18 b$<smiles>CCOC(=O)[C@]12C=CC[C@]1(C=O)CCCC2</smiles>

$79 \%$

$19 b$<smiles>CC(=O)OC[C@]12C=CC(C)(C)[C@]1(C)CCCC2</smiles>

$92 \%$

$31 \%$

Yield $^{\star}$

Isolated yield after flash silica gel column chromatography.

syn-configured vicinal quaternary stereocentres. These results highlight the robust nature of our method as a general strategy for the construction of ring systems of different sizes. The structure of $16 \mathrm{~b}$ was confirmed by X-ray crystallographic analysis.

It is particularly important that optically active molecules can be readily and reliably generated during the course of a total synthesis of natural product, because the optical properties of a molecule can have a significant impact on its biological activities. With this in mind, we evaluated the ability of optical enynols to undergo a stereospecific $[3+2]$ cycloaddition reaction without affecting their original enantiomeric excess (ee).

The chiral enynol ester 20 (97.7\% ee, Fig. 2) was readily synthesized from the corresponding chiral enynol via a coupling reaction with 2-bromo-4-nitrobenzoic acid. The application of the optimized annulation conditions to 20 resulted in the formation of the cycloaddition product 21 (97.5\% ee) in 95\% yield (Supplementary Figs 77 and 78). The stereochemistry of $\mathbf{2 1}$ was confirmed through X-ray crystallography. These results indicated that this $[3+2]$ cycloaddition reaction occurred in a stereospecific manner, and that the chirality of the substrate was effectively transferred to the product. quaternary carbon centres. The structure of $\mathbf{1 0 b}$ was confirmed by X-ray crystallographic analysis.

We also investigated the application of our newly developed reaction as a general method for the construction of $[4,3,0]$ ring systems (Table 3). Enynols 15a-19a were prepared and subjected to the optimized reaction conditions to afford the corresponding products 15b-19b in good-to-acceptable yields, bearing two

Mechanism investigation. Although the mechanism of this reaction is not completely elucidated, we proposed a mechanism to account for the stereochemical outcome of the reaction (Fig. 3a). It was envisaged that $\left[\mathrm{RhCl}(\mathrm{CO})_{2}\right]_{2}$ would react 

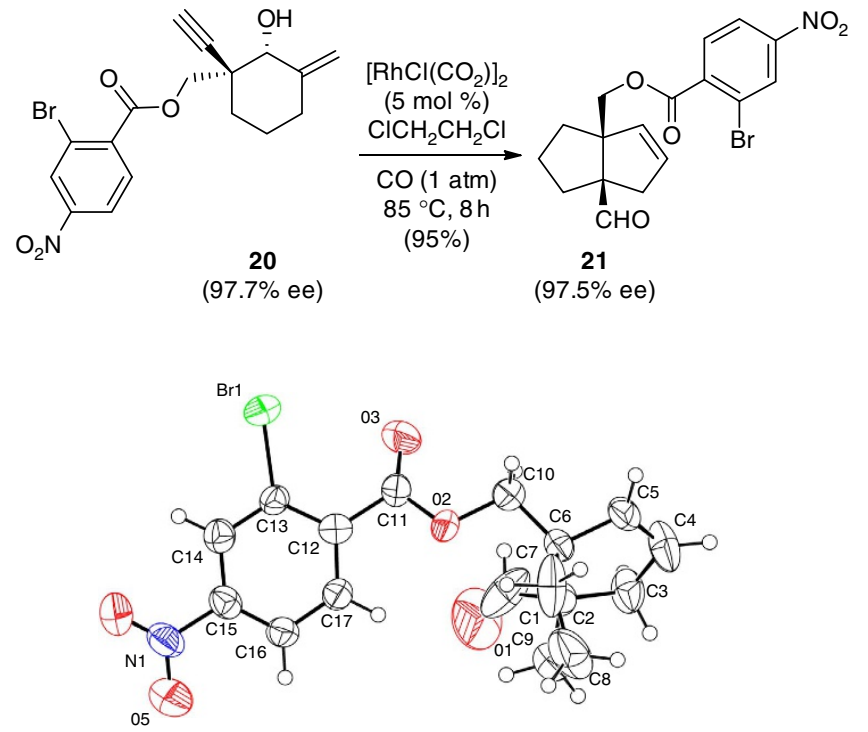

X-ray structure of 21

Figure 2 | Chirality transfer. Enantiomerically enriched substrate 20 underwent Rh-catalysed [3 +2 ] cycloaddition to yield enantiomerically enriched product $\mathbf{2 1}$.

with compound 7a to afford complex I (refs 50,51), which would undergo a $\mathrm{Rh}(\mathrm{I})$-mediated retro-propargylation of the homopropargyl alcohol to afford complex II (Fig. 3a).

Complex II would then undergo the intramolecular Michael addition $^{52-56}$ of the allenyl rhodium to the enal, to give the allenyl rhodium species III bearing an enolate moiety and a Rhcoordinate allene moiety. The transformation of III to IV can be interpreted as a Conia-ene ${ }^{57}$-type reaction between the Rhodaenolate species and the allene. Finally, protonolysis ${ }^{58-60}$ of complex IV with $7 \mathbf{a}$ would give product $\mathbf{7 b}$, which contains a [3.3.0] bicyclic ring moiety, together with the regeneration of complex I, which would allow for the completion of the catalytic cycle.

To support our proposed reaction mechanism, the deuterated enynol 22 was prepared as a probe to confirm that the $\mathrm{Rh}(\mathrm{I})$-catalysed retro- $\beta$-carbon elimination reaction was the key step in our catalytic cycle (Fig. 3a). The annulation of 22 under the optimized reaction conditions gave the desired product 23 in $78 \%$ yield with the retention of deuterium (Fig. 3b). This result indicated that the aldehyde substituent at the $\mathrm{C} 1$ position was generated via a $\mathrm{Rh}$-mediated $\mathrm{C}-\mathrm{C}$ bond cleavage reaction, rather than the oxidation of the corresponding alcohol.

Computational study. To further support our proposed reaction mechanism, density functional theory method M11-L, recently proposed by Peverati and Truhlar ${ }^{61}$, is employed to elucidate the mechanism of Rh-catalysed reaction cycle (Supplementary Tables 1 and 2). The free-energy profile, shown in Fig. 4, indicates that intramolecular retro metal propargylation from CP1 to CP2 occurs via a concerted transition state TS1 with an activation-free energy of $16.9 \mathrm{kcal} \mathrm{mol}^{-1}$. The allene-rhodium complex CP2 then forms reversibly, with the chirality of the allene being determined by the $\alpha$-carbon of the alkyne moiety in CP1. In CP2, the enone moiety is activated by rhodium (similar to the Lewis acid activation of enones), because the oxygen atom in the enone moiety coordinates to the rhodium atom. The second step, which is the rate limit, in this process is a relatively facile Michael-type addition of alleno-rhodium to the activated enone via TS2, with an activation-free energy of

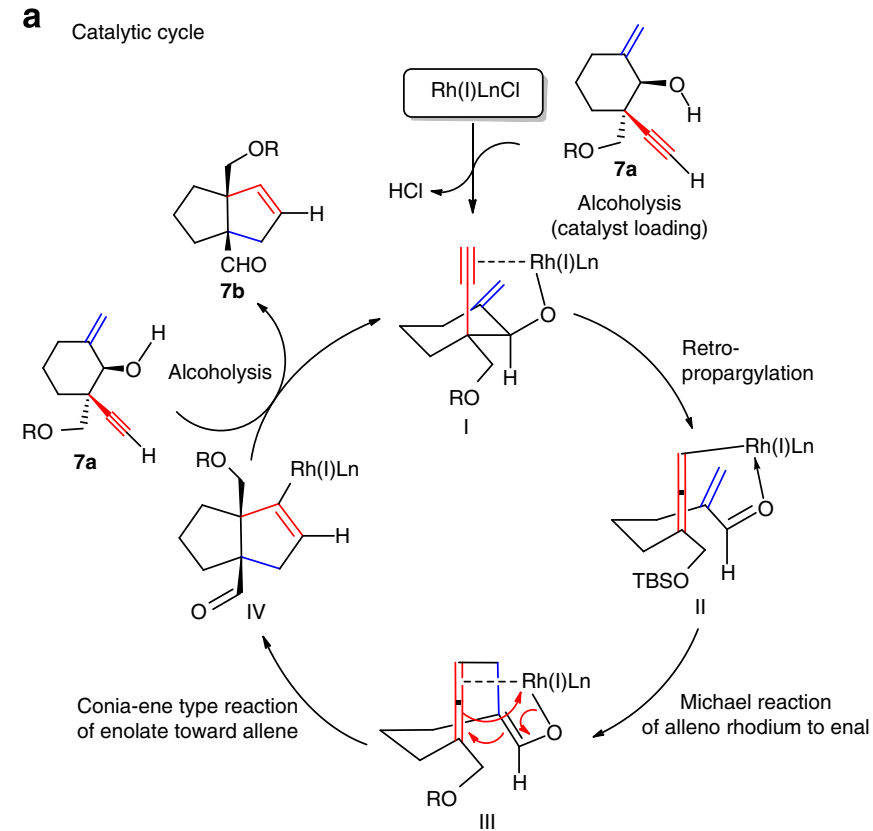

b

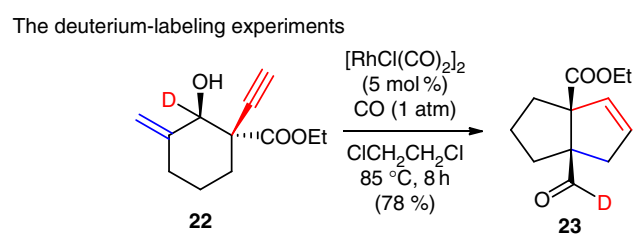

Figure 3 | Proposed Rh-catalysed reaction cycle and deuterium-labelling experiments. (a) The possible mechanism involves the sequential Rh-catalysed retro-propargylation/intramolecular Michael addition/ Conia-ene-type reaction/alcoholysis. (b) The deuterium-labelling experiments indicate that the aldehyde is generated via a Rh-mediated $\mathrm{C}-\mathrm{C}$ bond cleavage reaction.

$24.4 \mathrm{kcal} \mathrm{mol}^{-1}$. This Michael-type addition reaction affords intermediate CP3, which contains an enolate moiety and an allene moiety.

The allene moiety in $\mathbf{C P 3}$ is activated by its coordination to the rhodium centre. The subsequent reaction is alkylation of the enolate by the activated allene via a Conia-ene-type reaction. This alkylation step via TS3 is facile and gives the formal intramolecular [3+2] cycloadduct CP4, with an activation-free energy of $7.2 \mathrm{kcal} \mathrm{mol}^{-1}$. The last step is demetalation by the alcohol moiety of the substrate, which begins with ligand exchange between CP4 and the starting material 7a to give CP5. Next, the $\mathrm{C}-\mathrm{Rh}$ bond in complex CP5 is protonated via four-memberedring transition state TS4 (ref. 62). Following the release of product $\mathbf{7 b}$, the active intermediate $\mathbf{C P 1}$ is regenerated irreversibly to complete the catalytic cycle. This mechanism also well explains how the chirality in the starting molecule can be transferred to the final $[3+2]$ cycloadduct.

Total synthesis of $(-)$-lingzhiol. To demonstrate the utility of our newly developed methodology, we applied the annulation reaction in the asymmetric total synthesis of $(-)$-lingzhiol $(4)^{4}$. As a pair of rotary door-shaped meroterpenoidal enantiomers, $(-)$-lingzhiol (4) and its enantiomer $(+)$-lingzhiol were isolated from Ganoderma lucidum by Hou and colleagues ${ }^{4}$, who had to use $80 \mathrm{~kg}$ of $\mathrm{G}$. lucidum to obtain $25 \mathrm{mg}$ of both pure $(-)$ lingzhiol and $(+)$-lingzhiol. G. lucidum is a well-known 

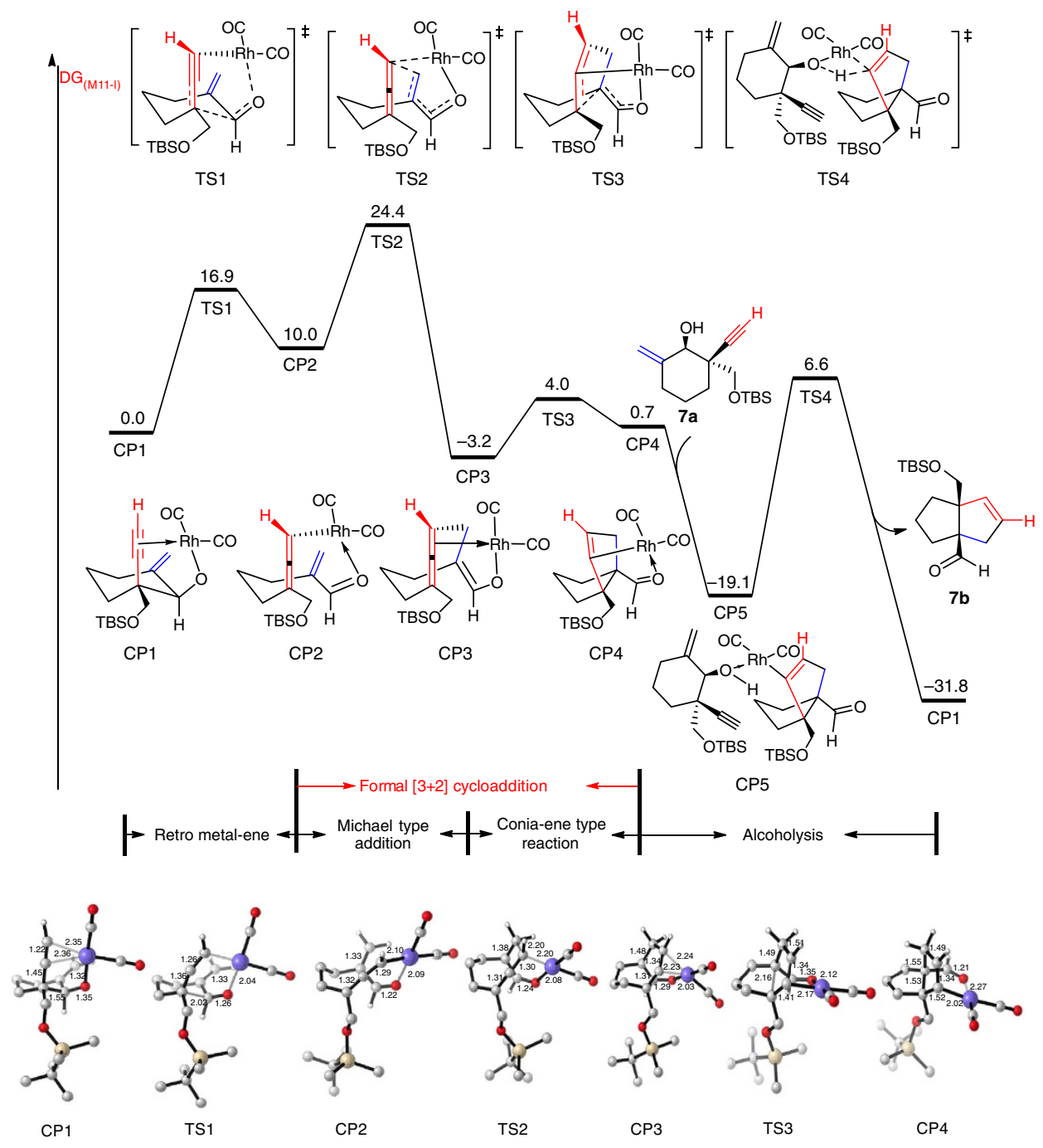

Figure 4 | Density functional theory calculations. Free-energy profiles and geometric information for catalytic cycle of rhodium-catalysed synthesis of bicyclo[3.3.0]octane $\mathbf{7 b}$.

mushroom that is used extensively in Asia as a super-grade medicine. Biological studies of the chemicals contained in this mushroom have indicated that both of the enantiomers of lingzhiols show potent and selective inhibitory activity towards the phosphorylation of Smad3 in transforming growth factor- $\beta 1$ induced rat renal proximal tubular cells and activate Nrf2/Keap1 in mesangial cells under diabetic conditions ${ }^{4}$. In light of the important biological activities of lingzhiol-type compounds and their potential application as lead compound for the development of therapeutic agents against chronic kidney disease, there is an urgent need for the development of a synthetic method capable of providing facile access to these materials to allow for detailed studies of their structure-activity relationship.

From a chemical perspective, ( - )-lingzhiol (4) represents a formidable challenge for total synthesis. (-)-Lingzhiol (4) possesses an intricate structure, which is decorated with two syn-configured vicinal quaternary carbon centres at the bridgehead carbons. This compound is also composed of a highly compact carbobicyclo[4.3.0] nonane core, which is known as a dihydroquinone-fused propellane. The development of an efficient synthesis for $(-)$-lingzhiol (4) that proceeds with good stereoselectivity would allow for the preparation of the natural product as well as its analogues in large-enough quantities to facilitate an adequate evaluation of their biological activities.
Our synthetic strategy was devised to provide rapid access to asymmetric synthesis of (-)-lingzhiol (4) and to address the synthetic issues associated with the construction of the highly compact carbobicyclo[4.3.0]nonane core belonging to this structural class. It was envisaged that our newly developed $\mathrm{Rh}$ catalysed intramolecular $[3+2]$ cycloaddition reaction could be used for the stereoselective formation of the carbobicyclo[4.3.0]nonane core of ( - )-lingzhiol (4), because this reaction would allow for the installation of the two bridgehead and synconfigured vicinal quaternary carbon centres in a single step.

Our retrosynthetic analysis of (-)-lingzhiol (4) is shown in Scheme 3. It was envisaged that the application of allylic oxidation, benzylic oxidation and demethoxylation reactions would allow for the successful elaboration and conversion of chiral lactone 24 into the final product ( - )-lingzhiol (4). Lactone 24 could be synthesized directly from the tricyclic precursor aldehyde 25 via a reductive lactonization reaction. The disconnections of the $\mathrm{C} 3^{\prime}-\mathrm{C} 7^{\prime}$ and $\mathrm{C} 4^{\prime}-\mathrm{C}^{\prime}$ bonds of 25 led to the homopropargyl alcohol 26, which could undergo our newly developed Rh-catalysed intramolecular $[3+2]$ cycloaddition reaction to form the tricyclic core of $\mathbf{2 5}$ in a diastereoselective manner. The chiral homopropargyl alcohol 26 could be prepared from enone 27 via sequential asymmetric ketone reduction with (R)-CBS/ $\mathrm{BH}_{3}$ (ref. 63), carboxylation and alkynylation ${ }^{64}$ 


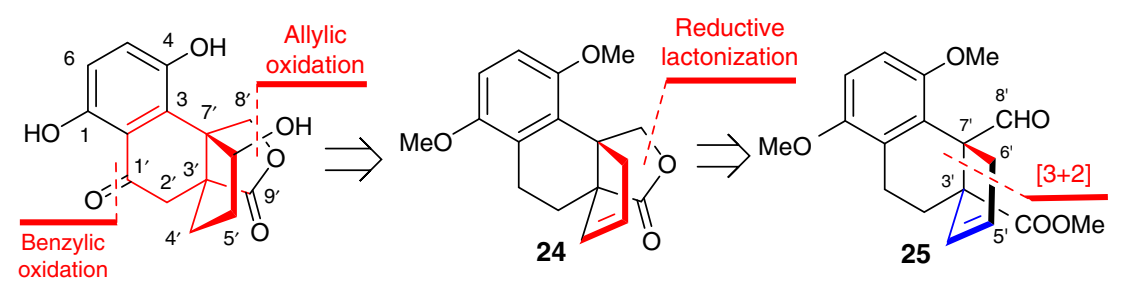

(-)-lingzhiol (4)

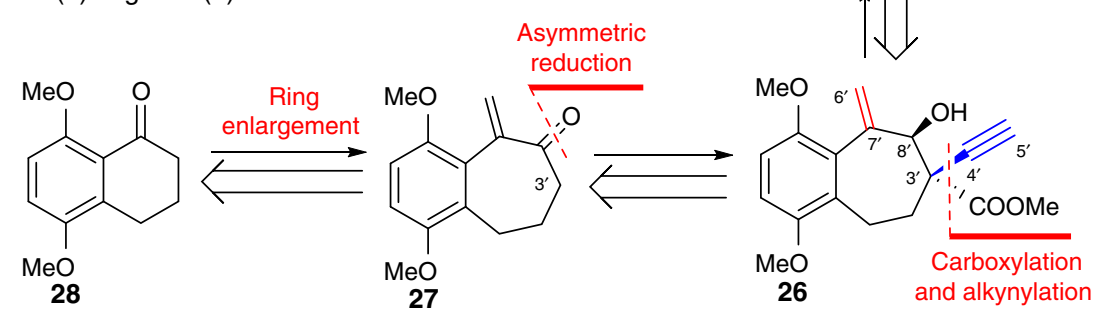

Figure $\mathbf{5}$ | Retrosynthetic analysis of $\mathbf{( - )}$-lingzhiol. The current Rh-catalysed [3+2] cycloaddition was used as a key step to construct the [4.3.0]-bicyclic ring moiety in ( - )-lingzhiol.<smiles>COc1ccc(OC)c2c1CCCC2=O</smiles>

32

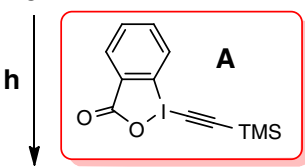<smiles>C#C[C@]1(C(=O)OC)CCc2c(OC)ccc(OC)c2C2(CO2)C1=O</smiles>

33<smiles>COc1ccc(OC)c2c1CCCC(=O)C2</smiles>

29<smiles>C=C1C(=O)CCCc2c(OC)ccc(OC)c21</smiles>

d<smiles>C=C1c2c(OC)ccc(OC)c2CCC[C@@H]1O</smiles>

30<smiles>COc1ccc(OC)c2c1CCCC(=O)[C@@]21CO1</smiles>

31<smiles>C#C[C@]1(C(=O)O)CCc2c(OC)ccc(OC)c2C(=C)C1=O</smiles>

34<smiles>C#C[C@]1(C(C)=O)CCc2c(OC)ccc(OC)c2C1=C</smiles>

26

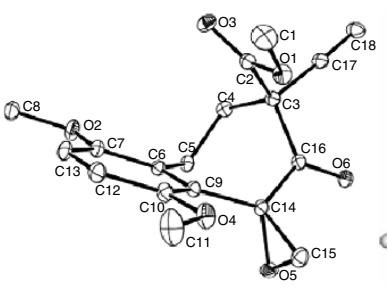

X-ray structure of 33

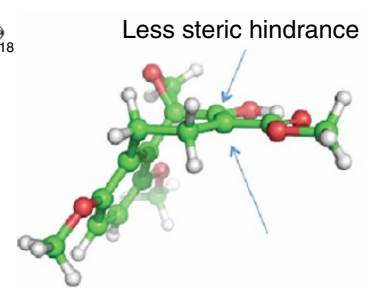

$3 D$ structure of 32

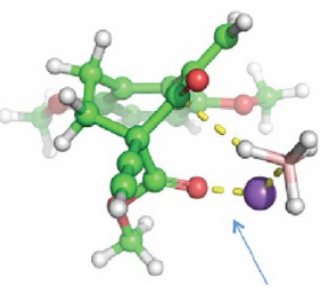

3D model of $\mathrm{NaBH}_{4}$ reduction of 34

Figure 6 Synthetic pathways for the construction of intermediate 26. (a) $\mathrm{PPh}_{3} \mathrm{CH}_{3} \mathrm{Br}, \mathrm{THF}, \mathrm{KHMDS} 0{ }^{\circ} \mathrm{C}$ to $25^{\circ} \mathrm{C}, 98 \%$; (b) $\mathrm{Phl}(\mathrm{OAc}) 2, \mathrm{p}-\mathrm{TSA}, \mathrm{MeCN}$, $0^{\circ} \mathrm{C}, 95 \%$; (c) $\mathrm{Et}_{3} \mathrm{~N} \cdot \mathrm{HCl}, \mathrm{Et}_{2} \mathrm{NH},\left(\mathrm{CH}_{2} \mathrm{O}\right)_{n}, 1,4$-dioxone, $105^{\circ} \mathrm{C}, 98 \%$; (d) (R)-CBS, $\mathrm{BH}_{3}, \mathrm{THF},-20^{\circ} \mathrm{C}, 91 \%$, 92\% ee; (e) meta-chloroperoxybenzoic acid ( $m$-CPBA), $\mathrm{NaHPO}_{4}, \mathrm{PhH}, 25^{\circ} \mathrm{C}$; (f) Dess-Martin periodinane, $\mathrm{NaHCO}_{3}, \mathrm{DCM}, 25^{\circ} \mathrm{C}, 81 \%$ for two steps; $(\mathbf{g}) \mathrm{LiHMDS}, \mathrm{NCCOOMe}, \mathrm{THF},-78^{\circ} \mathrm{C}$; (h) tetra-n-butylammonium fluoride, $\mathbf{A}$, THF, $-30{ }^{\circ} \mathrm{C}, 62 \%$ for two steps; (i) $\mathrm{Nal}, \mathrm{MeCN}, \mathrm{CF}_{3} \mathrm{COOH}, 0{ }^{\circ} \mathrm{C}, 92 \% ;(\mathbf{j}) \mathrm{NaBH}_{4}, \mathrm{CeCl}_{3} \cdot 7 \mathrm{H}_{2} \mathrm{O}, \mathrm{EtOH}^{\circ} \mathrm{O}^{\circ} \mathrm{C}$, 63\%. KHMDS: Potassium bis(trimethylsilyl)amide. 


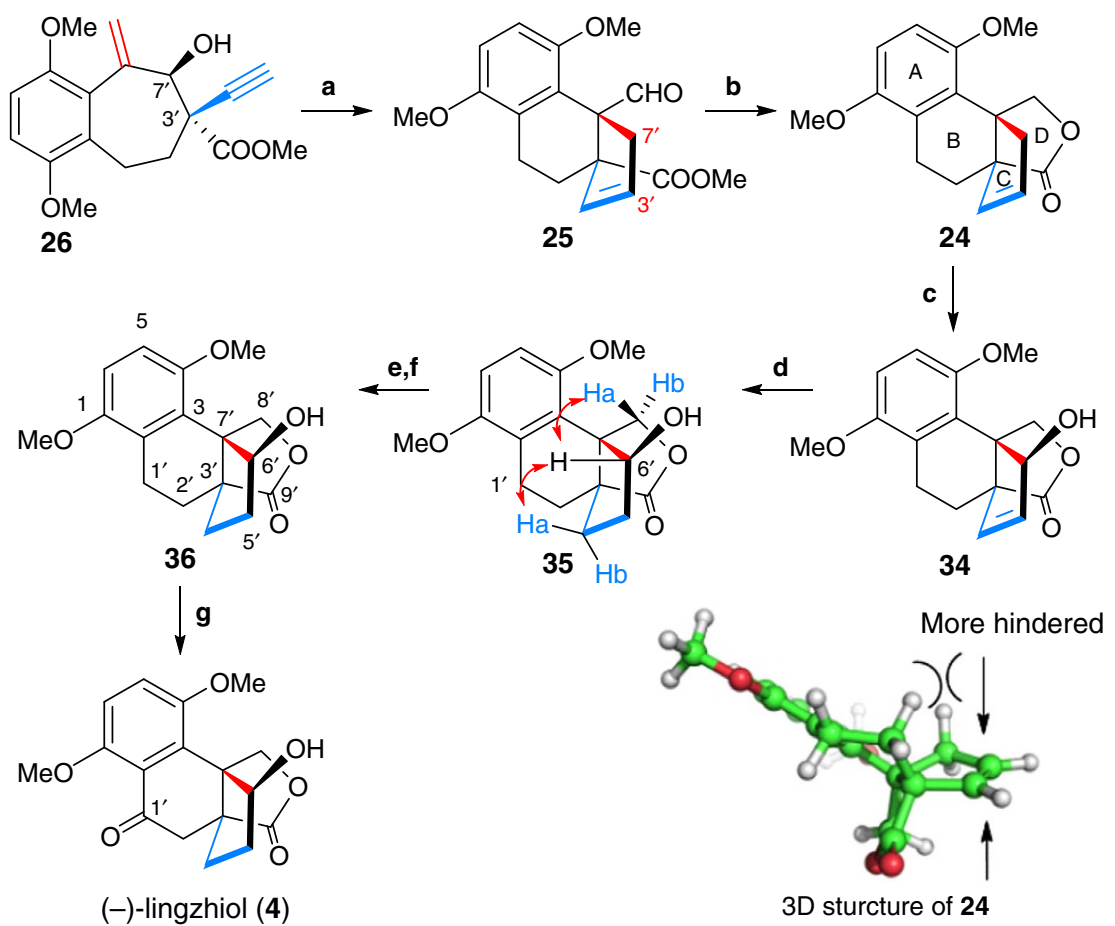

Figure 7 | Total synthesis of ( - )-lingzhiol. (a) $\left[\mathrm{Rh}(\mathrm{CO})_{2} \mathrm{Cl}\right]_{2}(5 \mathrm{~mol} \%), \mathrm{CO}, \mathrm{DCE}, 85^{\circ} \mathrm{C}, 86 \%$; (b) $\mathrm{NaBH}_{4}, \mathrm{MeOH}^{\circ} \mathrm{O}^{\circ} \mathrm{C}, 89 \%$; (c) $\mathrm{SeO}, 1,4-d i o x o n e$, $110{ }^{\circ} \mathrm{C}, 65 \%$; (d) $\mathrm{Pd}-\mathrm{C}(10 \%), \mathrm{H}_{2}, \mathrm{MeOH}, 25^{\circ} \mathrm{C}, 95 \%$; (e) $\mathrm{N}$-bromosuccinimide, benzoyl peroxide (BPO), $\mathrm{NaHCO}_{3}, \mathrm{H}_{2} \mathrm{O}, \mathrm{CCl}_{4}, 80^{\circ} \mathrm{C} ;(\mathbf{f}) \mathrm{MnO}_{2}, \mathrm{CH}_{2} \mathrm{Cl}_{2}$, $25^{\circ} \mathrm{C}, 71 \%$ for two steps; (g) ${ }^{\mathrm{t}} \mathrm{BuSH}, \mathrm{AlCl}_{3}, \mathrm{DCM}, 40^{\circ} \mathrm{C}, 71 \%$.

reactions. In this way, our retrosynthetic analysis was traced back to the preparation of enone 27 , which could be made from commercially available 5,8-dimethoxy-3,4-dihydronaphthalen1(2H)-one (28) (Fig. 5).

Our total synthesis of (-)-lingzhiol (4) began with the asymmetric preparation of the homo-propargyl alcohol 26 (Fig. 6). Treatment of commercially available 5,8-dimethoxy3,4-dihydronaphthalen-1 $(2 H)$-one (28) with a mixture of $\mathrm{Ph}_{3} \mathrm{PCH}_{3} \mathrm{Br}$ and potassium bis(trimethylsilyl)amide (KHMDS) in tetrahydrofuran (THF) resulted in the formation of the expected olefin in $98 \%$ yield, which was subsequently reacted with Koser's reagent ${ }^{65}$ in the presence of $p$-TSA in MeCN to give the benzoannulenone $\mathbf{2 9}$ in $95 \%$ yield via a ring-expansion reaction. Compound 29 was initially reacted with formyl aldehyde under a variety of different conditions. Unfortunately, however, the desired aldol reaction did not occur under these conditions, presumably because of the poor reactivity of formaldehyde. Alternatively, starting from Eschenmoser's salt, which was prepared by the reaction of formaldehyde with $\mathrm{Et}_{2} \mathrm{NH} \cdot \mathrm{HCl} /$ $\mathrm{Et}_{2} \mathrm{NH}$, the aldol reaction with ketone 29 in 1,4-dioxone at $105^{\circ} \mathrm{C}$ furnished the expected enone 27 in almost quantitative yield, which then subjected to an asymmetric reduction with $(R)$-CBS/ $\mathrm{BH}_{3}$ to afford the chiral allylic alcohol 30 in $91 \%$ yield with $94 \%$ ee.

With the chiral allylic alcohol $\mathbf{3 0}$ in hand, we turned our attention towards its elaboration to the key intermediate 26. To this end, allylic alcohol $\mathbf{3 0}$ was first subjected to a substratecontrolled asymmetric epoxidation by reaction with metachloroperoxybenzoic acid to afford an epoxide, which was then oxidized to ketone 31 in $81 \%$ yield in two steps by the treatment with Dess-Martin periodinane in the presence of $\mathrm{NaHCO}_{3}$ in $\mathrm{CH}_{2} \mathrm{Cl}_{2}$. To install the functional groups at its $\mathrm{C}^{\prime}$ position, ketone 31 was reacted with LiHMDS in THF at $-78^{\circ} \mathrm{C}$, followed by reaction with methyl carbonocyanidate to give the $\beta$-ketoester 32 as a pair of ketone-enol isomers. Compound $\mathbf{3 2}$ was found to be unstable and was therefore immediately reacted with Waser's reagent ${ }^{66}$ in the presence of tetra- $n$-butylammonium fluoride in
THF at $-30{ }^{\circ} \mathrm{C}$ to give compound 33 in $62 \%$ yield in two steps, together with $10 \%$ of its diastereisomer. The stereochemistry of 33 was confirmed through X-ray crystallography and the observed diastereoselectivity presumably occurred as a consequence of the less steric hindrance of the top face of $\mathbf{3 2}$ (see the three-dimensional (3D) structure of 32 in Fig. 6). Thus, the treatment of compound $\mathbf{3 3}$ with $\mathrm{NaI}$ in the presence of $\mathrm{CF}_{3} \mathrm{COOH}$ in $\mathrm{MeCN}$ provided ketoester 34 in $92 \%$ yield. Finally, the Luche reduction ${ }^{67}$ of ketoester 34 with $\mathrm{NaBH}_{4}$ in the presence of $\mathrm{CeCl}_{3} \cdot 7 \mathrm{H}_{2} \mathrm{O}$ in ethanol at $0{ }^{\circ} \mathrm{C}$ gave the homo-propargyl alcohol 26 in $63 \%$ yield as a single isomer. To account for the observed diastereoselectivity, we proposed that the ester group of 34 could coordinate with $\mathrm{NaBH}_{4}$ in such a way as to facilitate the delivery of the hydride to the ketone from its bottom face (see 3D model of complex 34 in Fig. 6).

We then proceeded to evaluate our newly developed Rhcatalysed $[3+2]$ cycloaddition reaction with the homo-propargyl alcohol 26 for the stereoselective construction of the critical intermediate 25, which featured two quaternary carbon centres at its bridgehead carbons (Fig. 7). Compound 26 was treated with $\left[\mathrm{RhCl}(\mathrm{CO})_{2}\right]_{2}(5 \mathrm{~mol} \%)$ at $85^{\circ} \mathrm{C}$ under an atmosphere of $\mathrm{CO}$ (balloon) in $\mathrm{ClCH}_{2} \mathrm{CH}_{2} \mathrm{Cl}$. Pleasingly, this reaction proceeded with excellent diastereoselectivity to give the desired product 25 in $86 \%$ yield. Subsequent treatment of 25 with $\mathrm{NaBH}_{4}$ gave lactone 24 in $89 \%$ yield, which was subjected to a $\mathrm{SeO}_{2}$-mediated allylic oxidation in 1,4-dioxane at $110^{\circ} \mathrm{C}$ to give the allylic alcohol 35 in $65 \%$ yield as a single diastereoisomer. The excellent diastereoselectivity observed in this reaction was attributed to the steric bulk over the top face of substrate 24, which would direct the $\mathrm{SeO}_{2}$ to approach the double bond from its bottom face (see the 3D structure of 24 in Fig. 7). Compound 35 was then subjected to a Pd-catalysed hydrogenation reaction to give product 36 in 95\% yield. The stereochemistry of $\mathbf{3 6}$ as depicted in Scheme 5 was determined by rotating-frame overhauser effect spectroscopy experiments. Furthermore, nuclear overhauser effect (NOE) experiments revealed a correlation between the $\mathrm{H}-6^{\prime}, \mathrm{Ha}-4^{\prime}$ and $\mathrm{H}-6^{\prime}$ protons. 
With the entire lingzhiol skeleton installed, all that remained was to introduce the final oxygen atom at $\mathrm{Cl}^{\prime}$ of $\mathbf{3 6}$ and remove its two methoxyl groups. Unfortunately, however, none of the typical benzylic oxidation reaction conditions tested resulted in the desired product 37. Given that the benzylic position could readily undergo a radical-mediated halogenation reaction, we designed a stepwise protocol involving sequential halogenation/ substitution/oxidation reactions to achieve this transformation. Following a period of experimentation, it was established that substrate 36 could be effectively converted to ketone 37 in $73 \%$ yield by the sequential treatment of $\mathbf{3 6}$ with $\mathrm{N}$-bromosuccinimide (NBS) in the presence of benzoyl peroxide ${ }^{68}$, as well as a trace amount of water in carbon tetrachloride, followed by $\mathrm{MnO}_{2}$ mediated oxidation of the resultant benzylic alcohol in $\mathrm{CH}_{2} \mathrm{Cl}_{2}$ at room temperature. Finally, removal of the both methoxyl groups of 37 with $\mathrm{AlCl}_{3}$ in the presence of an excess of ${ }^{t} \mathrm{BuSH}$ in $\mathrm{CH}_{2} \mathrm{Cl}_{2}$ resulted in the formation of $(-)$-lingzhiol in $78 \%$ yield. The spectroscopic data for the synthetic ( - )-lingzhiols were identical to the published values of the natural products ${ }^{4}$ and the optical rotation for ( - )-lingzhiol (4) was in good agreement with the literature values (Supplementary Tables $3-5$ ).

\section{Discussion}

In summary, we have developed a new intramolecular $[3+2]$ cycloaddition reaction between an enal and an alleno rhodium, which was generated in situ from the $\mathrm{Rh}(\mathrm{I})$-mediated retropropargylation of the corresponding homo-propargyl alcohol, to give [3.3.0] and [4.3.0] bicyclic ring systems with two quaternary carbon centres at their bridgehead positions. This reaction also allowed for the asymmetric synthesis when it was applied to chiral starting materials. To account for the observed reaction, we proposed a mechanism, which suggested that the reaction might involve an Rh-catalysed ring opening of a 2-alkynyl cycloalkanol moiety followed by the intramolecular $[3+2]$ cycloaddition on an alleno rhodium species to an enal. The application of this reaction to the synthesis of the natural product ( - )-lingzhiol has been also achieved for the first time in 17 steps from a commercially available starting material.

\section{Methods}

General. For ${ }^{1} \mathrm{H}$ and ${ }^{13} \mathrm{C}$ spectra of the compounds in this article, see Supplementary Figs 1-69. For ORTEP diagrams, see Supplementary Figs 70-76. For HPLC traces, see Supplementary Figs 77-79.

General procedure for the synthesis of $\mathbf{8 b} \mathbf{b} \mathbf{1 9 b}$. To a solution of an enynol in anhydrous $\mathrm{ClCH}_{2} \mathrm{CH}_{2} \mathrm{Cl}(0.025 \mathrm{M})$ was added $\left[\mathrm{RhCl}(\mathrm{CO})_{2}\right]_{2}(0.5 \mathrm{mg}, 1.25 \mu \mathrm{mol}$, $5 \% \mathrm{~mol}$ ) at $\mathrm{CO}$ atmosphere at room temperature and the mixture was degassed with $\mathrm{CO}$ for five times. The reaction mixture was then stirred at $85^{\circ} \mathrm{C}$ for the time listed in the Tables 2 and 3. After cooling to room temperature, the solvent was removed under vacuum and the residue was purified by a flash chromatography on silica gel to provide the desired product. For additional procedures, see Supplementary Methods.

\section{References}

1. Groweiss, A. et al. Subergorgic acid, a novel tricyclopentanoid cardiotoxin from the pacific gorgonian coral. Tetrahedron Lett. 26, 2379-2382 (1985).

2. Anke, T. et al. Crinipellins, the first natural products with a tetraquinane skeleton. Angew. Chem. Int. Ed. 24, 709-711 (1986).

3. Kaneda, M., Takahashi, R., Iitaka, Y. \& Shibata, S. Retigeranic acid, a novel sesterterpene isolated from the lichens of lobaria retigera group. Tetrahedron Lett. 13, 4609-4612 (1972).

4. Yan, Y.-M. et al. Lingzhiols, unprecedented rotary door-shaped meroterpenoids as potent and selective inhibitors of $p$-Smad3 from Ganoderma lucidum. Org. Lett. 15, 5488-5491 (2013).

5. Dong, L.-B. et al. Isopalhinine A, a unique pentacyclic lycopodium alkaloid from palhinhaea cernua. Org. Lett. 15, 3570-3573 (2013).

6. Boeckman, Jr R. K., Blum, D. M., Arnold, E. U. \& Clardy, J. The structure of gascardic acid from an X-ray diffraction study. Tetrahedron. Lett. 20, 4609-4694 (1979)
7. Hog, D. T., Mayer, P. \& Trauner, D. A unified approach to trans-hydrindane sesterterpenoids. J. Org. Chem. 77, 5838-5843 (2012).

8. Steven, A. \& Overman, L. E. Total synthesis of complex cyclotryptamine alkaloids: stereocontrolled construction of quaternary carbon stereocenters. Angew. Chem. Int. Ed. 46, 5488-5508 (2007).

9. Nicolaou, K. C., Vassilikogiannakis, G., Mägerlein, W. \& Kranich, R. Total synthesis of colombiasin A. Angew. Chem. Int. Ed. 40, 2482-2486 (2001).

10. Birman, V. B. \& Danishefsky, S. J. The total synthesis of ( \pm )-merrilactone A. J. Am. Chem. Soc. 124, 2080-2081 (2002).

11. Overman, L. E., Larrow, J. F., Stearns, B. A. \& Vance, J. M. Enantioselective construction of vicinal stereogenic quaternary centers by dialkylation: practical total syntheses of $(+)$ - and meso-chimonanthine. Angew. Chem. Int. Ed. 39, 213-215 (2000).

12. Crimmins, M. T. et al. Total synthesis of ( \pm )-ginkgolide B. J. Am. Chem. Soc. 121, 10249-10250 (1999).

13. Overman, L. E., Paone, D. V. \& Stearns, B. A. Direct stereo- and enantiocontrolled synthesis of vicinal stereogenic quaternary carbon centers. Total syntheses of meso- and ( -$)$-chimonanthine and $(+)$-calycanthine. J. Am. Chem. Soc. 121, 7702-7703 (1999).

14. Hatcher, J. M. \& Coltart, D. M. Copper(I)-catalyzed addition of Grignard reagents to in situ-derived $\mathrm{N}$-sulfonyl azoalkenes: An umpolung alkylation procedure applicable to the formation of up to three contiguous quaternary centers. J. Am. Chem. Soc. 132, 4546-4547 (2010).

15. Kikushima, K., Holder, J. C., Gatti, M. \& Stoltz, B. M. Palladium-catalyzed asymmetric conjugate addition of arylboronic acids to five-, six-, and seven-membered $\beta$-substituted cyclic enones: enantioselective construction of all-carbon quaternary stereocenters. J. Am. Chem. Soc. 133, 6902-6905 (2011).

16. Trost, B. M. \& Osipov, M. Palladium-catalyzed asymmetric construction of vicinal all-carbon quaternary stereocenters and its application to the synthesis of cyclotryptamine alkaloids. Angew. Chem. Int. Ed. 52, 9176-9181 (2013).

17. Zhang, Y. \& Danishefsky, S. J. Total synthesis of ( \pm )-aplykurodinone-1: traceless stereochemical guidance. J. Am. Chem. Soc. 132, 9567-9569 (2010).

18. Jiao, L., Lin, M. \& Yu, Z. -X. Rh(I)-catalyzed intramolecular [3+2] cycloaddition reactions of 1-ene-, 1-yne- and 1-allene- vinylcyclopropanes. Chem. Commun. 46, 1059-1061 (2010).

19. Yamago, S. \& Nakamura, E. Org. React. 61, 1-217 (2002).

20. Chan, D. M. T. in Comprehensive Organic Synthesis Vol. 3 (eds Trost, B. M. \& Fleming, I.) 271-314 (Pergamon, 1991).

21. Becker, D. A. \& Danheiser, R. L. A new synthesis of substituted azulenes. J. Am. Chem. Soc. 111, 389-391 (1989).

22. Zhang, C. \& Lu, X. Phosphine-catalyzed cycloaddition of 2,3-butadienoates or 2-butynoates with electron-deficient olefins. A novel [3+2] annulation approach to cyclopentenes. J. Org. Chem. 60, 2906-2908 (1995).

23. Lu, X., Zhang, C. \& Xu, Z. Reactions of electron-deficient alkynes and allenes under phosphine catalysis. Acc. Chem. Res. 34, 535-544 (2001).

24. Zhu, G. et al. Asymmetric [3+2] cycloaddition of 2,3-butadienoates with electron-deficient olefins catalyzed by novel chiral 2,5-dialkyl-7-phenylphosphabicyclo[2.2.1] heptanes. J. Am. Chem. Soc. 119, 3836-3837 (1997).

25. Wilson, J. E. \& Fu, G. C. Synthesis of functionalized cyclopentenens through catalytic asymmetric $[3+2]$ cycloadditions of allenes with enones. Angew. Chem. Int. Ed. 45, 1426-1429 (2006).

26. Cowen, B. J. \& Miller, S. J. Enantioselective [3+2]-cycloadditions catalyzed by a protected, multifunctional phosphine-containing $\alpha$-amino acid. J. Am. Chem. Soc. 129, 10988-10989 (2007).

27. Fang, Y. Q. \& Jacobsen, E. N. Cooperative, highly enantioselective phosphinothiourea catalysis of imine-allene [3+2] cycloadditions. J. Am. Chem. Soc. 130, 5660-5661 (2008).

28. Voituriez, A., Panossian, A., Fleury-Br_egeot, N., Retailleau, P. \& Marinetti, A. 2-Phospha[3]ferrocenophanes with planar chirality: synthesis and use in enantioselective organocatalytic [3+2] cyclizations. J. Am. Chem. Soc. 130, 14030-14301 (2008).

29. Sampath, M. \& Loh, T. -P. Highly enantio-, region- and diastereo-selective one-pot [2+3]-cycloaddition reaction via isomerization of 3-butynoates to allenoates. Chem. Sci. 1, 739-742 (2010).

30. Xiao, H. et al. Asymmetric [3+2] cycloaddition of allenoates and dual activated olefins catalyzed by simple bifunctional $\mathrm{N}$-acyl aminophosphines. Angew. Chem. Int. Ed. 49, 4467-4470 (2010).

31. Fujiwara, Y. \& Fu, G. C. Application of a new chiral phosphepine to the catalytic asymmetric synthesis of highly functionalized cyclopentenes that bear an array of heteroatom-substituted quaternary stereocenters. J. Am. Chem. Soc. 133, 12293-12297 (2011).

32. Zhang, X.-N. \& Shi, M. Phosphine-catalyzed [3+2] cycloaddition of 4,4-dicyano-2- methylenebut-3-enoates with benzyl buta-2,3-dienate and penta-3,4-dien-2-one. ACS Catal. 3, 507-512 (2013).

33. Han, X. Y., Wang, Y. Q., Zhong, F. R. \& Lu, Y. X. Enantioselective [3+2] cycloaddition of allenes to acrylates catalyzed by dipeptide-derived phosphines: 
facile creation of functionalized cyclopentenes containing quaternary stereogenic centers. J. Am. Chem. Soc. 133, 1726-1729 (2011).

34. Marshall, J. A., Gung, B. W. \& Grachan, M. L. in Modern Allene Chemistry Vol. 2 (eds Krause, N. \& Hashmi, A. S. K.) 493-592 (Wiley-VCH, 2004).

35. Krause, N. \& Hoffmann-Roder, A. Synthesis of allenes with organometallic reagents. Tetrahedron 60, 11671-11694 (2004).

36. Marshall, J. A. Chiral allylic and allenic metal reagents for organic synthesis. J. Org. Chem. 72, 8153-8166 (2007).

37. Ruitenberg, K., Kleijn, H., Meijer, J., Oostveen, E. A. \& Vermeer, P. Palladium(0)-promoted cross-coupling of allenylmetal compounds with aryl and vinyl iodides. A novel route to aryl- and vinyl-substituted allenes. J. Organomet. Chem. 224, 399-405 (1982).

38. Russell, C. E. \& Hegedus, L. S. Palladium-catalyzed acylation of unsaturated halides by anions of enol ethers. J. Am. Chem. Soc. 105, 943-949 (1983).

39. de Graaf, W., Boersma, J., van Koten, G. \& Elsevier, C. J. Chiral induction in the synthesis of 4,4-dimethyl-1-phenylpenta-1,2-diene (1-Ph-3-t-Bu-allene) catalyzed by chiral phosphine complexes of palladium. J. Organomet. Chem. 378, 115-124 (1989).

40. Werner, H., Rappert, T., Wiedemann, R., Wolf, J. \& Mahr, N. Mononuclear (allenylidene)metal complexes of a $\mathrm{d} 8$ system: synthesis and molecular structure of trans-[RhCl(:C:C:CRR')( $\left.\left.\mathrm{PiPr}_{3}\right)_{2}\right]$. Organometallics 13, 2721-2727 (1994).

41. Banerjee, M. \& Roy, S. Rhodium(I)-catalyzed carbonyl allenylation versus propargylation via redox transmetalation across tetragonal Tin(II) oxide. Org. Lett. 6, 2137-2140 (2004).

42. Werner, $\mathrm{H}$. et al. Unusual pathways for metal-assisted $\mathrm{C}-\mathrm{C}$ and $\mathrm{C}-\mathrm{P}$ coupling reactions using allenylidenerhodium complexes as precursors. J. Am. Chem. Soc. 124, 6966-6980 (2002).

43. Wang, J. -C., Ng, S. -S. \& Krische, M. J. Catalytic diastereoselective synthesis of diquinanes from acyclic precursors. J. Am. Chem. Soc. 125, 3682-3683 (2003).

44. Jones, R. A. \& Krische, M. Asymmetric Total synthesis of the iridoid $\beta$-glucoside $(+)$-geniposide via phosphine organocatalysis. Org. Lett. 11, 1849-1851 (2009).

45. Hayashi, S., Hirano, K., Yorimitsu, H. \& Oshima, K. Synthesis of arylallenes by palladium-catalyzed retro-propargylation of homopropargyl alcohols. J. Am. Chem. Soc. 130, 5048-5049 (2008)

46. Wender, P. A. et al. Transition metal-catalyzed [5+2] cycloadditions of allenes and vinylcyclopropanes: first studies of endo-exo selectivity, chemoselectivity, relative stereochemistry, and chirality transfer. J. Am. Chem. Soc. 121, 5348-5349 (1999)

47. Wender, P. A. et al. Transition metal-catalyzed [5+2] cycloadditions with substituted cyclopropanes: first studies of regio- and stereoselectivity. J. Am. Chem. Soc. 121, 10442-10443 (1999).

48. Wender, P. A. \& Christy, J. P. Rhodium(I)-catalyzed [4+2+2] cycloadditions of 1,3-dienes, alkenes, and alkynes for the synthesis of cyclooctadienes. J. Am. Chem. Soc. 128, 5354-5355 (2006).

49. Marshall, J. A. \& Robinson, E. D. A mild method for the synthesis of furans. Application to 2,5-bridged furano macrocyclic compounds. J. Org. Chem. 55, 3450-3451 (1990)

50. Zhao, P., Incarvito, C. D. \& Hartwig, J. F. Direct observation of $\beta$-aryl eliminations from Rh(I) alkoxides. J. Am. Chem. Soc. 128, 3124 (2006).

51. Zhao, P., Incarvito, C. D. \& Hartwig, J. F. Carbon-oxygen bond formation between a terminal alkoxo ligand and a coordinated olefin. Evidence for olefin insertion into a rhodium alkoxide. J. Am. Chem. Soc. 128, 9642 (2006).

52. Ma, S. \& Negishi, E.-I. Palladium-catalyzed cyclization of $\omega$-haloallenes. A new general route to common, medium, and large ring compounds via cyclic carbopalladation. J. Am. Chem. Soc. 117, 6345-6357 (1995).

53. Gibson, S. E., Guillo, N., Middleton, R. J., Thuilliez, A. M. \& Tozer, J. Synthesis of conformationally constrained phenylalanine analogues via 7-, 8- and 9-endo Heck cyclisations. J. Chem. Soc. Perkin Trans. 1, 447-456 (1997).

54. Takasu, K., Mizutani, S., Noguchi, M., Makita, K. \& Ihara, M. Stereocontrolled total synthesis of $( \pm)$-culmorin via the intramolecular double michael addition. Org. Lett. 1, 391-393 (1999).

55. Burns, A. R., McAllister, G. D., Shanahan, S. E. \& Taylor, R. J. Total Synthesis and structural reassignment of $(+)$-dictyosphaeric acid A: a tandem intramolecular michael addition/alkene migration approach. Angew. Chem. Int. Ed. 49, 5574-5577 (2010).

56. Takasu, K., Mizutani, S., Noguchi, M., Makita, K. \& Ihara, M. Total Synthesis of $( \pm)$-culmorin and $( \pm)$-longiborneol: an efficient construction of tricyclo[6.3.0.03,9] undecan-10-one by intramolecular double michael addition. J. Org. Chem. 65, 4112-4119 (2000).
57. Conia, J. M. \& Le Perchec, P. The thermal cyclisation of unsaturated carbonyl compounds. Synthesis 1, 1-19 (1975).

58. Senda, T., Ogasawara, M. \& Hayashi, T. Rhodium-catalyzed asymmetric 1,4-addition of organoboron reagents to 5,6-dihydro-2(1H)-pyridinones. asymmetric synthesis of 4-aryl-2-piperidinones. J. Org. Chem. 66, 6852-6856 (2001).

59. Hayashi, T., Takahashi, M., Takaya, Y. \& Ogasawara, M. Catalytic cycle of rhodium-catalyzed asymmetric 1,4-addition of organoboronic acids. arylrhodium, oxa- $\pi$-allylrhodium, and hydroxorhodium intermediates. J. Am. Chem. Soc. 124, 5052-5058 (2002).

60. Sun, Z.-M. \& Zhao, P. Rhodium-mediated decarboxylative conjugate addition of fluorinated benzoic acids: stoichiometric and catalytic transformations. Angew. Chem. Int. Ed. 48, 6726-6730 (2009).

61. Peverati, R. \& Truhlar, D. G. Improving the accuracy of hybrid meta-GGA density functionals by range separation. J. Phys. Chem. Lett. 2, 2810-2817 (2011).

62. Shi, F.-Q. Density functional theory study on the mechanism of Rh-catalyzed decarboxylative conjugate addition: diffusion- and ligand-controlled selectivity toward hydrolysis or $\beta$-hydride elimination. Org. Lett. 13, 736-739 (2011).

63. Corey, E. J., Bakshi, R. K. \& Shibata, S. Highly enantioselective borane reduction of ketones catalyzed by chiral oxazaborolidines mechanism and synthetic implications. J. Am. Chem. Soc. 109, 5551-5553 (1987).

64. Poulsen, T. B., Bernardi, L., Alemán, J., Overgaard, J. \& Jørgensen, K. A. Organocatalytic asymmetric direct $\alpha$-alkynylation of cyclic $\beta$-ketoesters. J. Am. Chem. Soc. 129, 441-449 (2007).

65. Justik, M. W. \& Koser, G. F. Oxidative rearrangements of arylalkenes with [hydroxy(tosyloxy)iodo]benzene in 95\% methanol: a general, regiospecific synthesis of $\alpha$-aryl ketones. Tetrahedron Lett. 45, 6159-6163 (2004).

66. Gonzàlez, D. F., Brand, J. P. \& Waser, J. Ethynyl-1,2-benziodoxol-3(1 H)-one (EBX): an exceptional reagent for the ethynylation of keto, cyano, and nitro esters. Chem. Eur. J. 16, 9457-9461 (2010).

67. Luche, J.-L. Lanthanides in organic chemistry. 1. Selective 1,2 reductions of conjugated ketones. J. Am. Chem. Soc. 100, 2226-2227 (1978).

68. Nomura, K., Okazaki, K., Hori, K. \& Yoshii, E. Total synthesis of

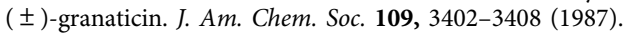

\section{Acknowledgements}

We thank Professors Zhixiang Yu of Peking University and Junmin Quan of Peking University Shenzhen Graduate School for their helpful discussions. This work is sup ported by the National Science Foundation of China (grant numbers 21372016 and 21402002), 863 Program (grant number 2013AA092903), 973 Program (grant numbers 2010CB833201 and 2012CB722602), NSFC-Shandong Joint Fund for Marine Science Research Centers (U1406402) and Shenzhen Basic Research Program (grant numbers JCYJ20130329180217059, GJHS20120628101219325, ZYC201105170335A and ZYC201105170358A)

\section{Author contributions}

R.L. and J.H. contributed equally to this work. R.L., J.H. and Z.Y. conceived the project and analysed the experimental results. R.L., J.H., W.S. and J.G. performed the synthesis and characterization. S.L. and Y.L. performed the theoretical calculations. Y.L., J.G. and Z.Y. composed the manuscript with input from all authors.

\section{Additional information}

Accession codes: The X-ray crystallographic coordinates for structures reported in this article have been deposited at the Cambridge Crystallographic Data Centre (CCDC), under deposition numbers CCDC 1026082-1026089. These data can be obtained free of charge from the Cambridge Crystallographic Data Centre via http://www.ccdc.cam. ac.uk/data_request/cif

Supplementary Information accompanies this paper at http://www.nature.com/ naturecommunications

Competing financial interests: The authors declare no competing financial interests

Reprints and permission information is available online at http://npg.nature.com/ reprintsandpermissions/

How to cite this article: Long, R. et al. Asymmetric total synthesis of ( - )-lingzhiol via a Rh-catalysed $[3+2]$ cycloaddition. Nat. Commun. 5:5707 doi: 10.1038/ncomms6707 (2014). 